\section{LOS LIBROS DE CAZA MEDIEVALES Y SU INTERÉS PARA LA HISTORIA NATURAL}

\author{
José Manuel Fradejas Rueda \\ Universidad de Valladolid \\ ORCID iD: http://orcid.org/0000-0001-8603-6765 \\ josemanuel.fradejas@uva.es
}

\section{MEDIEVAL HUNTING BOOKS AND THEIR INTEREST FOR NATURAL HISTORY}

Cómo citar este artículo/Citation: Fradejas Rueda, J. M. (2017). Los libros de caza medievales y su interés para la historia natural. Arbor, 193 (786): a413. doi: http://dx.doi.org/10.3989/ arbor.2017.786n4002

Recibido: 30 abril 2015. Aceptado: 04 febrero 2016.

RESUMEN: En la introducción se expondrán los tres tipos básicos de caza: defensiva, ofensiva y lúdica. Esta es la que desde antiguo ha sido codificada y registrada en los libros de caza, un género que nace en Grecia y que durante el período grecolatino tiene un mínimo cultivo. Será en la Edad Media cuando el género tenga un mayor desarrollo y surgirá un nuevo tipo de tratado: el de cetrería, un subgénero netamente medieval y que sucumbirá con la aparición de las armas de fuego. Tanto los libros de montería como de cetrería son una interesante fuente de información sobre el medio natural parcamente explorada, máxime cuando dos tratados medievales castellanos, escritos en la primera mitad del siglo XIV, el Libro de la caza de don Juan Manuel y el Libro de montería del rey Alfonso, se cierran con sendas guías de caza en las que se describen, a veces escuetamente a veces minuciosamente, los territorios en los que se podía cazar, en qué época y qué especies eran las más abundantes, e incluso, en el caso de la montería, cómo se debían de disponer las partidas de caza.

PALABRAS CLAVE: Caza; cetrería; montería; Edad Media; libros de caza; historia; ecología.
Copyright: (c) 2017 CSIC. Este es un artículo de acceso abierto distribuido bajo los términos de la licencia Creative Commons Attribution (CC BY) España 3.0.

ABSTRACT: Protective, utilitarian and sport hunting are the basic types of hunting and will be defined in the introduction. Hunting for pleasure is the only type that has been coded and recorded in the hunting books and treatises, a genre that was born in Ancient Greece but had minimal output during the Greco-Roman period. It was not until the Later Middle Ages that the genre was developed further and a new kind of treatise emerged, devoted to falconry, a distinctly medieval subgenus. As an aristocratic pastime, falconry later declined in popularity, partly due to the refinement of firearms. Books and treatises on falconry and on chasse courant, or chasse par force, are a very interesting source of information for environmental studies, as yet sparsely explored for their significance. During the XIV-century in the Kingdom of Castile, the Libro de la caza by Juan Manuel, a falconry treatise, and the Libro de la montería by King Alfonso, a book on the chasse par force, were written. Although they deal with two different hunting methods, they both consist of guides to the best hunting locations. Some places are just named or briefly mentioned but others are minutely described and also provide other useful information. This includes the quarry most likely to be found there, information about the hunting seasons, dangerous spots and where they are located, and in the case of chasse par force, how and where huntsmen and relays should be most favourably placed.

KEYWORDS: Hunting; falconry; Middle Ages; literature; hunting books; history; ecology. 


\section{INTRODUCCIÓN}

La caza era uno de los dos medios básicos que el hombre primitivo tenía para proveerse de alimento; el otro era la recolección de frutos que encontraba. Sin embargo, no se ha de pensar que eran unos meros depredadores asistemáticos que vivían al día, que cazaban lo que encontraban a su paso. Todo lo contrario, los primitivos pobladores practicaban una «depredación provisoria», es decir, tenían un sistema organizativo que les permitía subsistir aplicando las mejores estrategias para cubrir las necesidades alimenticias que cada grupo humano tenía de acuerdo con las condiciones medioambientales en las que vivía (Quesada López, 1998). Según se fueron transformando las sociedades nómadas, de cazadores-recolectores en sociedades sedentarias y agrarias, la caza dejó de ser la fuente principal de alimentos y pasó a tener otras consideraciones en el discurrir del tiempo. Fue transformándose, según acontecían los avances tecnológicos, culturales y sociales, hasta el punto que en cierto momento puede hablarse de tres modalidades básicas de caza: la caza defensiva, la caza ofensiva y la caza lúdica. Estos tres tipos de caza son los que han perdurado hasta prácticamente el siglo pasado.

Los campesinos, desde siempre y en cualquier época y lugar, se han visto obligados a defenderse de las alimañas que podían diezmar y esquilmar sus cultivos y ganados. Osos, lobos, zorros o jabalíes, por solo nombrar los más grandes, podían ser un auténtico problema. Los tres primeros podían atacar, y de hecho atacaban, los rebaños. Numerosas narraciones folclóricas hablan de los ataques de lobos y zorros a ovejas, cabras o vacas que tranquilamente se apacentaban en los prados o estaban recluidas en sus apriscos. Los jabalíes pueden, en pocos minutos, arrasar todo un sembrado. Los osos podían hacer «muy gran daño en el ganado, principalmente en las colmenas» (Terrón Albarrán, 1984, p. 416). La documentación de todo tiempo y lugar habla de las quejas de los campesinos a causa de los problemas que estas fieras ocasionaban en sus medios de subsistencia. Así surge una de las modalidades básicas de la caza: la caza defensiva, en la que los hombres tratan de proteger y defender sus tierras y animales, incluso sus propias vidas.

Los campesinos y villanos no cazaban tan solo para controlar las alimañas que pudieran perjudicarles a ellos y sus medios de subsistencia. Por medio de la caza conseguían un buen complemento para su alimentación, pues era un medio excelente para obtener carne, especialmente liebres, conejos y algunas aves, sobre todo perdices. También les proporcionaba pie- les que utilizaban para su vestimenta y equipamiento doméstico (Cantera Montenegro, 1997, p. 42). Esta caza da lugar a que aparezca la figura del cazador profesional, para el que la caza se convertía en un medio de vida de donde obtenía los recursos necesarios para su subsistencia, no un mero complemento como lo era para el campesinado, por lo que se la designa como caza ofensiva.

Una idea recurrente, desde siempre, es que la «la actividad cinegética se convierte en ocasiones en un objeto de diversión o deporte de algunas personas» (García Cañón, 2002, p. 91). Sin embargo, la idea del mero divertimento no cabe en la mentalidad antigua. No existe el ocio por el ocio. Eso es algo que se consigue en las sociedades postindustriales en las que el tiempo libre es una de las grandes conquistas sociales. En épocas pasadas todo lo que se hacía tenía un fin, un propósito. Así, la caza no era simplemente un divertimento, aunque pudiera producir placer y diversión, como muy bien afirma don Juan Manuel en el siglo XIV, cuando, en el Libro de los estados, dice que uno de sus mayores plazeres era "caçar con aves e con canes». Es lo mismo que dirá a finales de ese siglo Gastón Phébus (Tilander, 1971) «tout mon temps me suis delité par espicial en trois choses, l'une est en armes, l'autre est amours, et l'autre si est en chasce» ( $p$. 51) así que el «bon venour [...] aura assez de joye, de liesce et de deduit» (p. 52) «[e]t, pour ce je loe et conseille a toute maniere de gent, de quel que estar que il soyent, qu'il aiment les chiens et les chasses et deduiz ou d'une beste ou d'autre ou d'oysiaus» (p. 57).

Sin embargo, tanto para este como para Juan Manuel, la caza tiene otros componentes más importantes que el mero divertimento. Para el primero la caza «[p]remierement hon en fuit touz les sept pechiez mortelz [...] toutes bonnes coustumes et muers en viennent et la salvation de l'arme, quar, qui fuit les sept pechiez mortelz, selon nostre foy il devroit estre sauvé» (p. 52) y «secondement hon est mielz chevauchant et plus viste et plus entendant et plus apert et plus aisié et plus entreprenent et mieulx cognoissent touz pays et tous passages» (p. 52). Mientras que el segundo presenta en su Libro de los estados un minucioso programa educativo para los hijos de los nobles quienes de lunes a sábado deben pasar la semana «leyendo un día et caçando otro" y

[...] si fuere de hedat que pueda andar a cavallo et sofrir la fortaleça del tiempo, non deve dexar, por fuerte tienpo que faga, de ir a caça en cavallo [...] et quando andudiere a caça, deve traer en la mano derecha lança o ascoña o otra vara; et en la isquierda 
deve traer un açor o un falcón. et esto deve fazer por acostumbrar los braços: el derecho, para saber ferir con él, et el isquierdo, para usar el escudo con que se defienda [...] et deve poner espuelas al cavallo, a vezes por lugares fuerte, et a vezes por llanos, por que pierda el miedo de los grandes saltos et de los lugares fuertes et sea mejor cavalgante.

Como puede apreciarse, la caza es la escuela básica del militar -caballero, miles- medieval. Pero no solo para el entrenamiento físico, como acabamos de ver, sino que esta academia también le sirve al señor para conocer mejor sus tierras y sus gentes.

No se trata de un hallazgo del hombre medieval, ya en la Grecia clásica la caza era uno de los pilares de la educación del ciudadano, como nos lo hace saber Jenofonte en su Cynegeticon:

Yo aconsejo a los jóvenes que no desprecien la caza ni el resto de la educación, pues por ella se hacen expertos en las cosas de la guerra y en las demás que exigen pensar, hablar y obrar correctamente.

Es preciso que el que ya deja atrás la infancia se dedique, primero, al ejercicio de la caza y, luego, a las demás enseñanzas.

Esta caza lúdica, durante la edad media y el renacimiento, se presenta bajo dos modalidades básicas: la montería, que se conocía como correr monte, y la cetrería, o caça con aves, o como lo expresaban los cazadores franceses del medievo: los deduis de chiens y los deduis des oyseaux. Aunque no siempre se dieron estas dos modalidades, pues la cetrería, los deduis des oyseaux, son una modalidad que aparece en Europa con la caída del Imperio Romano (Van den Abeele, 1996, p. 35).

\section{LOS LIBROS DE CAZA}

Tanto la caza lúdica como la ofensiva ha sido objeto de codificación por escrito. Así, en el siglo IV a. C. nace de la mano de Jenofonte una rica literatura didáctica relativa a la caza o a sus auxiliares destinada principalmente a un público que la practica (Van den Abeele, 1996, p. 29).

Esta larga historia, que se inicia con el Cynegetico de Jenofonte, es relativamente breve y pobre en el mundo grecolatino. En los casi diez siglos que median desde la aparición de la obra de Jenofonte y la caída del Imperio Romano, solo se compusieron cinco obras, curiosamente todas tituladas de igual manera: Cynegeticos - debidas a Jenofonte (s. IV a. C.), Gratio (s. I a. C - I d. C.), Arriano (s. II d. C.), Nemesiano (s. III d. C.) y Oppiano (s. III d. C)-. Ahí se abre un gran paréntesis hasta que en el siglo $x$ surge la primera obra de cetrería, el anónimo de Vercelli, y se inicia una nueva, rica y copiosa tradición que en gran medida oscurecerá los demás tratados de caza: los de la chasse par force.

En cualquier caso, ya sean libros de cetrería ya lo sean de montería, un buen número de ellos atesora muchos datos básicos para la historia de la veterinaria por el sencillo hecho de que perros y aves de rapiña se han usado como poderosas armas de caza, pero como seres vivos podían padecer enfermedades o sufrir accidentes y había que cuidarlos con mimo y esmero, por eso numerosos tratados de caza dedican amplías secciones a los aspectos médicos, quirúrgicos y farmacológicos. Además, tanto perros como aves de cetrería son descritas con detalles minuciosos, tanto desde el punto de vista morfológico, como de su distribución. En el caso de las aves de cetrería -falcónidas y accipitrinas- ofrecen información detallada sobre los territorios de cría y, aunque a veces es difícil interpretar los datos, pueden permitir un estudio comparativo con el momento actual. Si se acepta la información que ofrece Juan Manuel en su Libro de la caza (cap. IV), los halcones sacres fueron aves que habitaron en la Península Ibérica, pues era posible capturarlos a orillas del Valderaduey y en los encinares de Mayorga y Villalpando y, según López de Ayala, criaban en Escandinavia (cap. V), pero los informes actuales no hablan de la existencia de sacres (Falco cherrug) en Europa occidental.

Puesto que para enseñar a cazar hay que conocer con detalle las piezas que se quieren capturar (osos, ciervos, jabalíes, ánades, garzas, etc.) así como sus hábitats, estos textos contienen descripciones de gran interés para la historia natural. Algunos de ellos incluso permiten reconstruir la distribución de las diversas especies que eran objeto de caza y la de otras no tan interesantes desde el punto de vista cinegético. Muchos de los datos que esos libros ofrecen se han visto confirmados por la arquezoología, es decir, por el estudio arqueológico de los restos de animales, básicamente huesos, que se han localizado en los diversos yacimientos arqueológicos. Otros, muy pocos en verdad, son una rica fuente para conocer la toponimia de tiempos pasados, el paisaje, las especies que existen en un determinado punto y en qué época del año abundan y es el momento más adecuado para cazarlas.

Sin embargo, lo primero que se ha de hacer es definir qué se entiende por libro de caza, pues nos movemos ante un amplísimo abanico de posibilidades tanto de contenido, puede ser un recetario para curar 
los halcones, como una detallada obra sobre la caza del oso o del jabalí; puede presentarse bajo diversas formas literarias: tratado sistemático en prosa -Libro de la montería, Livre de la chasse de Gaston Fébus, De arte venandi cum avibus-, recetario-Dancus Rex, Libro de los azores-, diálogos -Diálogos de la montería-, debate -Livres du roy Modus et de la royne Ratio-, poema para instruir -Libro de cetrería de Luis de Zapata o el Dels auzels cassadors de Daude de Prada-, como de extensión, desde apenas unas pocas hojas a gruesos volúmenes. De esta amplia muestra de formas pueden excluirse obras alegóricas como el Libro de cetrería de Evangelista, un tratadito castellano que parodia la caza de cetrería (Fradejas Rueda, 1988; Fradejas Rueda, 1992a) o todos los referidos a la chasse amoreux (Thiébaux, 1974).

Un elemento que todos los libros de caza tienen en común es que se trata de textos didácticos con un fin utilitario, por lo general escritos por expertos en el tema, a veces personajes de los que apenas si conocemos su nombre -Valerino, Gerardus, Guillemus-, a veces son reyes como Alfonso de Castilla -Libro de la montería-, Federico II de Hohenstaufen-De arte venandi cum avibus- o João I de Portugal -Livro da montaria-; otras grandes nobles aficionados a la caza como Juan Manuel -Libro de la caza-, Pero López de Ayala -Libro de la caza de las aves-, Gaston Fébus - Livre de la chasse-, Edward, duque de York-Master of Game- o Gace de la Buigne -Le roman des deduis-, o cazadores profesionales como Pero Menino -Livro de falcoaria- o Juan de Sahagún -Libro de cetrería-. A veces se ocuparon de ello eruditos de la talla de Adelardo de Bath -De curis accipitrum- o Alberto Magno -De falconibus et asturibus- y otras se atribuyeron a personajes ficticios -Dancus- o de conocida reputación, como Hipócrates, para prestigiar los textos que anónimos escritores compusieron (Fradejas Rueda, 1998, pp. 19-20; Van den Abeele, 1994, p. 26).

Por otra parte, no todos los libros de caza tratan los mismos asuntos. Unos se ocupan de la selección y entrenamiento de los auxiliares de la caza-perros o aves de cetrería-; otros de las enfermedades y accidentes que pueden padecer y de los cuidados que se les han de dar; otros del conocimiento, búsqueda y concierto de las piezas que se quieren cazar; otros de los mejores lugares para practicar la caza, otros abordan la materia de manera más enciclopédica y tratan de ofrecer una visión completa tanto de la cetrería como de la montería -Libro de cetrería y montería de Juan Vallés (1556) o el Arte de ballestería y montería de Alonso Martínez de Espinar (1644)-.
Durante la Edad Media, desde el siglo x, hasta las postrimerías del Renacimiento hay tres tipos de libros de caza que dominan el panorama: los de cetrería, los que tratan la caza mayor -montería- y los de caza menor y de alimañas, aunque esto último se encuentra sobre todo en los libros de venación franceses, como se evidencia en la obra de Gastón Phébus.

Además, los libros de caza se pueden dividir en razón de las lenguas en las que fueron redactados. Hasta el siglo XIII, pero también lo encontraremos durante los siglos siguientes, la única lengua posible para los libros de caza es el latín ${ }^{1}$, pero desde el siglo XIII hasta la actualidad se escribirán en las diversas lenguas vulgares de Europa. Además, con una curiosa distribución: los libros de cetrería pueden estar escritos en latín o en cualquier lengua vulgar, pero los de caza mayor, montería, solo se encuentran en lenguas vernáculas.

Una excelente definición de los libros de caza, aunque limitada a la época medieval, que es la de mayor interés, es la que ofrece Van den Abeele (1996). Para este investigador un "traité cynégétique [est] un écrite didactique relatif à la chasse et / ou à ses auxilaires -quadrupède ou oiseau de chasse-, composé en latin ou en langue vulgaire, et destiné en principe à un public de praticiens» (p. 29). Cualquier texto cuyo contenido no entre en la definición anterior no debe tenerse en cuenta a la hora de estudiar la caza en tiempos pasados, otra cosa es que puedan ser útiles para completar el panorama.

Van den Abeele (1996, p. 76) sostiene que los libros de caza no son un buen campo para el estudio histórico del medio natural ya que hay serios problemas de lengua, pues aunque «les traités cynégétiques tiennent le langage le plus concret sur les animaux» (1996, p. 77), es muy difícil identificar correctamente las diversas especies que mencionan. Por ejemplo, en los tratados de cetrería castellanos el ornitónimo cuervo puede servir para designar a tres especies claramente diferenciadas y que solo se pueden individualizar por medio del adjetivo que las especifica: cuervo carnicero correspondería al Corvux corax, el cuervo marino al Phlalocrocorax carbo y el cuervo calvo al Geronticus eremita.

Según López de Ayala, entre las aves que se alimentan de insectos y pequeños mamíferos se encuentran los tartalanes y los budalones y entre las anátidas los trullos y las capisayadas, pero no sabemos de qué especies se trata, a pesar de los esfuerzos por identificarlos (Bernis, 1995). A veces la filología y la ornitología comparadas han permitido identificar alguna variedad como es el 
caso de la averramía (y las varias formas bajo las que aparece): se ha identificado positivamente como la espátula (Platalea leucorodia) (Fradejas Rueda, 1990).

A pesar de los posibles problemas lingüísticos que estos viejos tratados puedan encerrar, muchas veces debido a los errores de transmisión textual a lo largo de los siglos (Fradejas Rueda, 1999; Fradejas Rueda, 2002a), los tratados de caza pueden ser una importante e interesante fuente de información para la historia ecológica. Ya han servido para la historia de la veterinaria y de la farmacopea, pero el medio natural se ha resentido debido al acientifismo de los datos que ofrecen los libros de caza, también ha habido una cierta prevención porque la caza y la ecología (más bien el ecologicismo) son dos mundos abiertamente enfrentados. Sin embargo, las meras observaciones, que eso es lo que abunda en los libros de caza, son datos que han de ser interpretados y valorados a la luz de los conocimientos actuales. Así, en el De arte venandi cum avibus, libro de cetrería redactado por Federico II de Hohenstaufen (1194-1250), en el capítulo 1.55 se pone como ejemplo de la migración altitudinal la perdiz pardilla (Perdix perdix): «de montibus ad convales tempore hiemis et de valibus ad montana tempore estatis, ... ut perdices» (Trombetti Budriesi, 2000, pp. 72-74). Eso es un mero dato observacional y por tanto incontestable y, en consecuencia, valioso.

En este sentido los libros de caza españoles son una riquísima fuente de información. Hay dos obras que destacan entre todas las demás debido a que incorporan un apartado que es exclusivo del mundo hispánico: el Libro de caza de don Juan Manuel y el Libro de la montaría del rey Alfonso ${ }^{2}$. Estas dos obras contienen unos catálogos muy detallados de los mejores lugares de caza que había en el reino de Castilla en el siglo XIV, lo que permite estudiar con detenimiento una serie de espacios naturales cuya única característica en común es la de ser cazaderos: uno de aves, el otro de jabalíes (Sus scrofa) y osos (Ursus arctos) y, ocasionalmente, de encebros (Equus hydruntinus). Uno recorre ríos, el otro montes. Tanto las unas como las otras han sido estudiadas desde diversas perspectivas. La más usual es la toponímica (Ruhstaller 1995; Ruhstaller, 1996), pero también se ha abordado desde la perspectiva del cazador (Terrón Albarrán 1998; Terrón Albarrán, 2002; Terrón Albarrán, 2008), de los estudios locales (Andrés, 2000) o de la geografía (Martínez Carrillo, 1982).

\section{EL LIBRO DE LA CAZA}

El Libro de la caza se debe a la pluma del Príncipe don Juan Manuel, nieto de Fernando III el Santo, so- brino de Alfonso X el Sabio y abuelo de Juan I. Este noble castellano redactó un pequeño tratado de cetrería que decía seguir el modelo de su tío Alfonso X. No se sabe cuál pudo ser esa obra alfonsí y por eso durante mucho tiempo se ha considerado la única obra original, que no seguía ningún modelo anterior, de la cetrería española. Sin embargo, se ha podido demostrar que sigue el esquema y modelo, muy adelgazado, del De arte venandi cum avibus de Federico II de Hohenstaufen (Fradejas Rueda, 2005).

El contenido se presenta perfectamente estructurado. Comienza por ofrecer una clasificación de las aves de caza (cap. 1) ${ }^{3}$, los motivos por los cuáles él prefiere la caza con halcón que con azor (cap. 2) para pasar a la descripción y elección de los mejores halcones (cap. 3), su amansamiento (cap. 4), afeitamiento (cap. 5), especialización (caps. 6 garceros, 7 grueros y 8 que no sean raleones) y caza (cap. 9). En el décimo capítulo se introduce en un aspecto delicadísimo en la vida de las aves: la muda, y en el undécimo toca, someramente, las enfermedades y su cura, tema por el que Juan Manuel no sentía ningún interés, pero se vio forzado, por el peso de la tradición, a incluirlo. En definitiva, no se ha salido del esquema tradicional de los libros de cetrería (Fradejas Rueda, 1998, p. 8):

1. Informaciones ornitológicas

2. Informaciones cinegéticas

3. Régimen higiénico

4. Información veterinaria

Por este motivo habría sido, a pesar de su ilustre fuente, uno más entre muchos otros textos cetreros. Sin embargo, presenta una sección absolutamente novedosa y que no tiene reflejo en ninguna otra tradición cetrera europea: como último capítulo incorpora una detallada descripción, salpicada de anécdotas y protestas de no ser chufador, es decir, bromista, de las mejores riberas y zonas lacustres para la práctica de la cetrería - «Xuela nasçe en la xierra sobre Villar del Forno et entra en Guadiana cerca de Arenas» (p. 204) ${ }^{4}$, «El arroyo de Rello nasçe sobre Rello et entra en el arroyo de Berlanga sobre Catalojar» (p. 206)-. En ella señala qué raleas (especies) se pueden encontrar en cada trecho de un río o zona húmeda - «La tierra de Chincella ha muchas lagunas en que ha muchas ánades, et, en algunas, flamenques» (p. 192); «Et el río de Sangunera viene de Lorca et entra en la huerta de Murçia, et do entra en la huerta, ay muchas garças et bítores» (p. 195)-, en qué época del año y la cantidad -«ay muchas grúas en ivierno et en verano, mas las 
del ivierno son muchas más» (p. 199), "et al tienpo de la çimençera et de las uvas ay muchas grúas, et lo demás siempre ay dos o tres pares de grúas de morada» (p. 201), «[e]n este arroyo ha muchas ánades desque faze grant ivierno» (p. 202), «en la laguna et en ese canpo [...] ay muchas ánsares bravas, et bienen ý ante de Nabidat et fincan ý fasta la entrada de março» ( $p$. 203) - y las dificultades que puede presentar la zona - «muy mala ribera de cavalgar porque ay muchos armajales et muy malos pasos» (p. 192); «todo es agora carrizales et almarjales et muy malos pasos» (p. 205); «salvo por do va por hozes et grandes angosturas de peñas» (p. 207)-.

Este interesantísimo y muy poco explorado, salvo desde el punto de vista toponímico, capítulo se inserta para indicar

qué caças ha et qué lugares para las caçar en las tierras que don Johan a andado. Et esto fizo don Johan porque quando él acaesçiese en algunas de las tierras que en este libro son escriptas et se non acordare de los nonbres de las riberas o de los pasos o de los lugares, que los pueda saber leyendo en este libro, porque pueda fallar la caça más çierta et más sin trabajo et la pueda caçar más a su voluntad; et esto mismo podrán fazer todos los que este libro tovieren et leyeren tan bien en su vida de don Johan como después (p. 192).

Y para que sea más sencillo de manejar

púsolo todo por obispados. Et fabla primeramente de las caças et de los lugares que an para las caçar en el obispado de Cartagena, et después en el obispado de Cuenca, et después en el obispado de Çigüença, et [después] en el obispado de Osma, et después en el obispado de Palençia, et después en el [arçobispado] de Burgos, et después en el obispado de Calahorra, et después en el obispado de León, et después en el obispado de Estorga, et después en el obispado de Çamora, et después en el obispado de Salamanca, et después en el obispado de Ávila, et después en el obispado de Sogovia, et después en el arçobispado de Toledo, et después en el obispado de Jahén, et después en el obispado de Córdoba, et después en el arçobispado de Sevilla, et después en la tierra de la orden de Sanctiago que ellos llaman tierra de León (p. 192).

Desafortunadamente solo se han conservado los tres primeros obispados de los quince prometidos, los de Cartagena, Cuenca y Sigüenza (mapa 1). El manuscrito se interrumpe con estas palabras: «Pues es acabado de contar las riberas que don Johan sabe en el obispado de Çigüença, dirá d'aquí adelante de las riberas que él sabe en el obispado de Osma».

\section{EL LIBRO DE LA MONTERÍA}

La otra gran obra de gran valor para la historia de la ecología peninsular es el Libro de la montería ${ }^{5}$. Esta obra, de la que se han conservado trece copias manuscritas producidas durante los siglos XIV y XV, a las que hay que añadir al menos cinco más que existían a principios del siglo XVI (Fradejas Rueda, 2002b, p. 788), se divide en tres libros. En el primero habla de los rastros, perros y monteros; el segundo lo dedica a «la física de los canes» y en el tercero, el más extenso, presenta "los montes que a en el nuestro señorio». Como libro de caza su valor es escaso ya que casi todo el material propiamente venatorio carece de originalidad ${ }^{6}$ puesto que bebe de fuentes conocidas. Así, una parte del libro primero (caps. 38-41) y todo el libro segundo derivan del Libro de los animales que cazan, traducción castellana, finalizada en 1252, del tratado árabe Kitab al-yawarih (Fradejas Rueda, 1987). El tercer libro, el más extenso, 290 folios por las dos caras de los 357 que conforman el códice Y.II.19 de El Escorial, es realmente lo más novedoso y original de toda la obra y que en gran medida puede atribuirse al rey Alfonso $\mathrm{XI}^{7}$.

El libro III es, como ya he adelantado, el único de interés para la historia de la ecología peninsular. No abarca todo el territorio, tan solo zonas escogidas del reino de Castilla y León, por lo que quedan excluidos Portugal, Navarra, Aragón y el reino nazarí de Granada (mapa 2). A lo largo de 30 capítulos describe, de manera muy monótona, más de 1.560 montes $^{8}$. Estas descripciones van desde las escuetas en las que se informa del nombre del monte, qué tipo de caza es posible encontrar y en qué época -«El monte de Caloca es bueno de oso en verano» (p. 55b) ${ }^{9}$, «Las gargantiellas de las cabeçuelas que estan sobre Bohoyo es buen monte de osso en verano» (p. 81a), «El Çarçalejo et Ual de Çelada es todo vn monte, et es bueno de puerco en ynujerno; et a uezes ay osso» (p. 106a), «La sierra de Solchite es buen monte de puerco en yuierno, et ay muchas enzebras; et en este monte ay una fuente quel dizen de Salzeio» (p. 125b)- hasta las más completas en las que se indica, además, en dónde se han de situar las bozerías (ojeadores que con sus gritos levantan la caza y la dirigen), las armadas (líneas de cazadores que esperan la pieza levantada en el lugar más predecible que saldrá) y los renuevos (lugares donde se sitúan los perros de refresco):

La Onbria de Piedra Fita es buen monte de osso en ynuierno. Et son las bozerias la vna por çima de la cunbre de la sierra; et la otra desde el atalayuela, por çima del Çerro de la Pellona ayuso fasta el can- 
Mapa 1. Obispados mencionados por don Juan Manuel y secuencia de descripción prometida. Sombreadas las zonas descritas en el MSS/6376 de la Biblioteca Nacional de España.

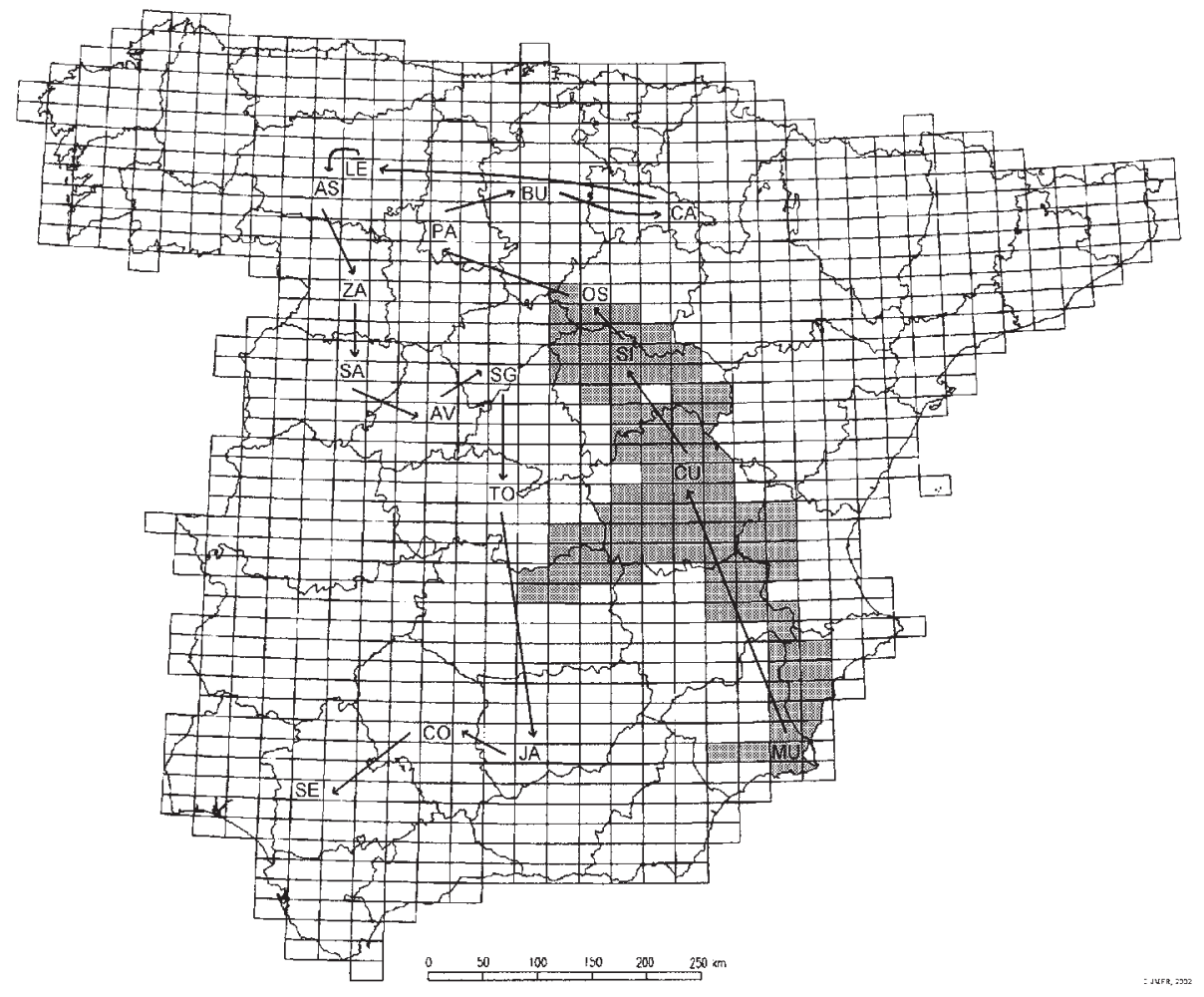

Mapa 2. Zonas en las que se ubican los montes mencionados en el libro III del Libro de la montería. Los números indican el capítulo en el que se exponen. Basado en Valverde (2009, p. 21).

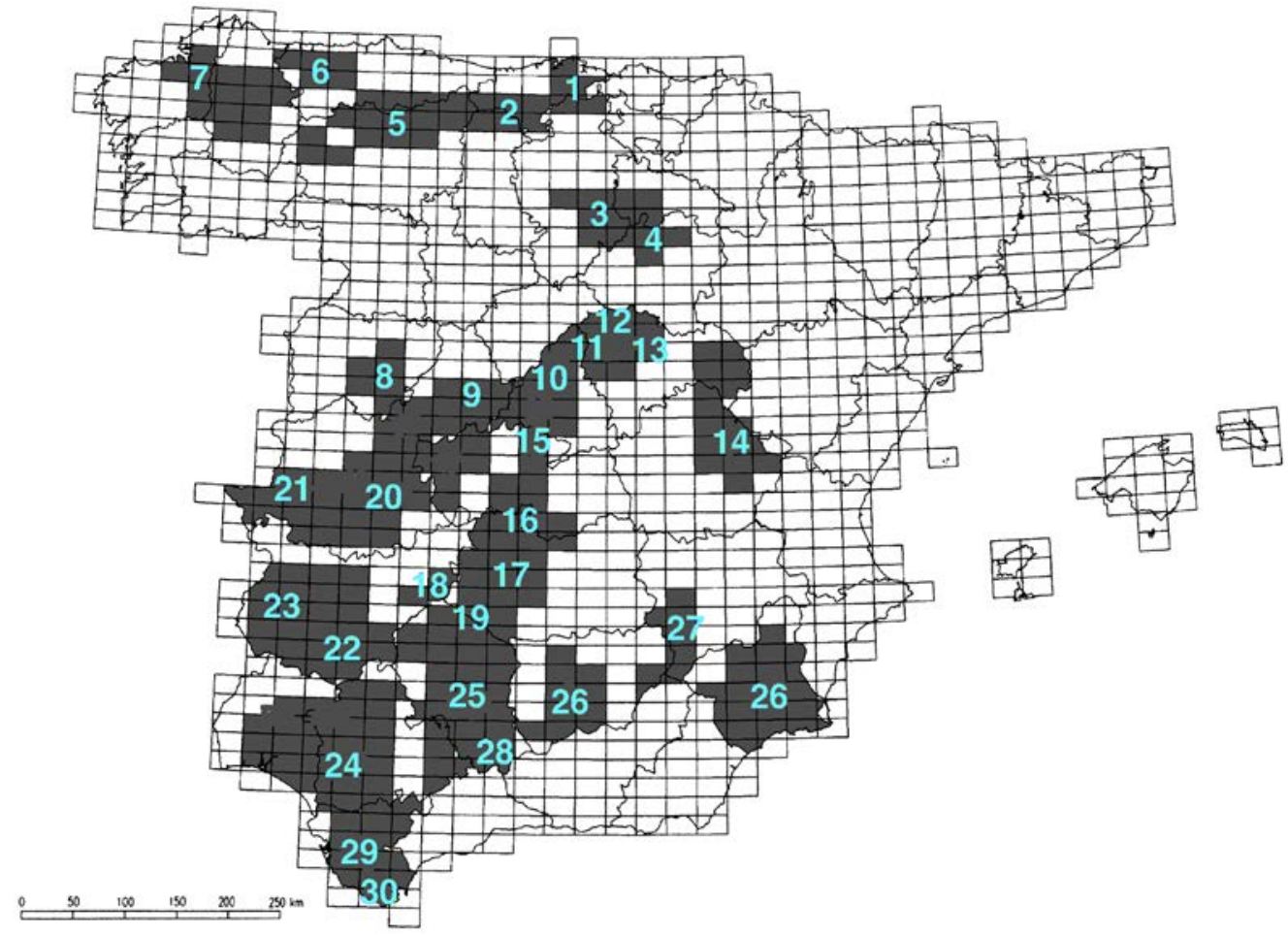


po; et la otra por el Çerro de Garueña ayuso, que este a espaldas del armada. Et que esten canes de rrenueuo en Naual Çerro, et en el Çerro del Azeueda, et en el Çerro del Fortigal. Et es el armada en Naua Cabrera (p. 81a-b)

El monte de la Lanchosa es bueno de osso en todo tienpo. Et son las bozerias la vna en el Arroyo de la Lanchosa de la parte de Val Fondo, et la otra en cima de los çerros a par del Camjno de Monte Moljn. Et son las armadas la vna en el puerto del Camjno de Monte Moljn, et la otra sobre las colmenas de Alfonso Martin (p. 118b).

Estas descripciones, que comienza en el valle de Mena, en Tierra de Castilla la Vieja, recorren las principales sierras hasta llegar a la zona de Gibraltar - «los montes de termino de Tarifa, et de Algezira»-, aunque, como cabe esperar, deja amplias zonas inexploradas (mapa 2). Esta tediosa relación, a veces rápida, a veces detallada, la ameniza con algún que otro relato personal como cuanto cuenta cuándo cazó por primera vez en la tierra de Algeciras - «La primera vez que corri este monte, mate en el vn osso de los grandes que nunca vj. Et fue el primero osso que maté en tierra de Algezira» (p. 134b)-, o la noche que pasó persiguiendo una osa en la zona del actual embalse de Melonares (Sevilla) (p. 116a-b), o los dos días, lunes y martes después de Pascua Florida (¿de 1344?), que duró la caza de un oso en la Sierra de Sancti Spíritus (Badajoz) (pp. 107-108), o los cuatro osos que mataron, de los diez que localizaron, en la sierra de los Ibores (Cáceres) (p. 105b).

Aparte de la localización de estas especies cinegéticas -oso, jabalí, encebro y raramente el ciervo-, el Libro de la montería es de gran valor porque permite reconstruir el paisaje; aunque para ello haya que basarse en los topónimos, a veces no son tales, sino meras designaciones descriptivas de los lugareños que informaron a los monteros del rey Alfonso, en los que abundan los fitónimos -arrayán, carrizo, aliso, almarjo, algarrobo, almez, acebuche, retama, lentisco, tejo, madroño, etc.-, los zoónimos -águila, buitre, ciervo, culebra, halcón, gavilanes, etc.- y orónimos -bodonal, collado, cuevas, barranco, angostura, guijo, lomo, lanchar, etc.-. Algo han intentado investigadores como Terrón Albarrán (1998, 2002, 2008) o Valverde (2009), que son quienes más se han acercado al análisis del Libro de la montería. Aquel con los ojos del cazador historiador, este con los del biólogo que hace escarceos en libros históricos ${ }^{10}$.
Un aspecto importante e interesante es el procedimiento de compilación de la información recogida en el Libro de la montería. A ello ha dedicado Ruhstaller (2012) un interesante trabajo, al que nada cabe añadir.

\section{CONCLUSIÓN}

La caza, actividad que ha desarrollado el ser humano desde sus orígenes, ha sido objeto de una rica producción escrita que se presenta como una interesantísima e inexplorada fuente de datos para la historia del medio natural: los libros de caza. Un tipo de escrito pensado para instruir a los que la practicaban y cuyos orígenes se remontan a la Grecia clásica, aunque el gran desarrollo se dio a partir de la Edad Media, desde el siglo x. Estos textos han sido estudiados con pasión desde el punto de vista filológico; no en vano, antes de que otros especialistas los puedan utilizar, los críticos textuales los han de estabilizar y fijar. Pero también los han analizado los historiadores de la veterinaria y la farmacología y en menor medida los historiadores de la ciencia. Aunque ha habido algunos escarceos desde el ámbito de las ciencias naturales -botánica, zoología y ecología-, solo se ha hecho tardía y puntualmente, a pesar de que los libros de caza españoles encierran una valiosísima información no presente en ninguna otra tradición cinegética europea.

La verdad es que el Libro de la caza de don Juan Manuel y el Libro de la montería son dos obras que se completan y que podrían haber ofrecido la mejor fuente para conocer el medio natural del reino de Castilla y León durante el siglo xIV. Lamentablemente, el estado fragmentario del primero nos ha privado de los datos pertinentes para la cuenca del Duero, el Ebro y el Guadalquivir, lo cual ofrece un panorama truncado. A pesar de ello, los datos que ambos textos ofrecen son de sumo interés y gran valor para trazar la historia del medio natural de una gran parte de España que, además, se puede contrastar con los datos, parciales y no muy exactos, de las relaciones topográficas que Felipe II mandó realizar en los años de 1570.

\section{AGRADECIMIENTOS}

Este trabajo no se ha realizado bajo los auspicios de ningún proyecto, pero toma sus datos y resultados de dos proyectos financiados, por el ministerio correspondiente en cada momento, entre los años 2006 y 2013 e identificados por las referencias HUM2006-00932/FILO y FFI2010-15128 titulados Archivo Iberoamericano de Cetrería y cuyos resultados son accesible en www.aic.uva.es. 


\section{NOTAS}

1. Evidentemente me estoy refiriendo a la Europa occidental; no incluyo ni considero en este trabajo el mundo árabe ni el bizantino.

2. Lo usual es indicar que el autor de esta obra es el rey Alfonso XI (1311-1350); sin embargo, es una obra cuyos orígenes se remontan al rey Alfonso $X$ (1221-1284) y parece que debió de llegar a la redacción definitiva bajo la cual se nos ha transmitido durante el reinado de Pedro I (1334-1369), lo cual ha dado lugar a un amplio debate académico (Fradejas Rueda, 1992b; Ruhstaller, 2012).

3. Juan Manuel ofrece una clasificación mucho más amplia en el Libro del caballero y del escudero (cap. 41) Puede verse un análisis en Fradejas Rueda (2000).

4. Todas las citas del Libro de la caza proceden de Fradejas Rueda (2001, pp. 127-208). Para aligerar solo se mencionará la página de donde procede la cita.

5. Hay otras obras que también encierran información de valor como es el Tratado de montería del siglo xv, o los

\section{BIBLIOGRAFÍA}

Andrés, G. (2000). Las cacerías en la provincia de Madrid en el siglo XIV según el Libro de la montería de Alfonso XI. Madrid: Fundación Universitaria Española.

Bernis, F. (1995). Diccionario de nombres vernáculos de aves. Madrid: Gredos.

Cantera Montenegro, E. (1997). La agricultura en la Edad Media. Madrid: Arco Libros.

Fradejas Rueda, J. M. (1986). La originalidad en la literatura cinegética. Epos: Revista de Filología, 2, pp. 75-88.

Fradejas Rueda, J. M. (1987). Libro de los animales que cazan $=$ Kitāb al-Ŷawārih . Madrid: Editorial Casariego.

Fradejas Rueda, J. M. (1988). Manuscritos y ediciones del "Libro de Cetrería» de Evangelista. En: Varia bibliographica: homenaje a José Simón Díaz (vol. 1) Kassel: Reichenberger, pp. 283-288.

Fradejas Rueda, J. M. (1990). La averramía: nota léxica. Epos: Revista de Filología, 6, pp. 447-484. tratados de cetrería y montería que se escribieron durante el siglo XVI e incluso XVII como el Libro de acetrería y montería de Juan Vallés, el Libro de cetrería de caza de azor de Fadrique de Zúñiga y Sotomayor (1565). En muchos casos ofrecen informaciones locales de gran interés. Así, sabemos que las últimas poblaciones descritas del ibis eremita las menciona Luis de Zapata a finales del siglo XVı y las sitúa en Extremadura. medieval es un tanto problemático puesto que es un concepto moderno que no entraba en la escala de valores de tiempos pasados. Para una discusión acerca de la originalidad de la literatura cinegética véase Fradejas Rueda (1986)

7. No puedo compartir la idea de Valverde (2009, p. 19) de que se inspirara en uno preexistente de Alfonso $X$, pues no hay prueba alguna, aunque tenemos información de que el rey Sabio escribió libros de caza, no sabemos realmente cuál era su contenido.

8. Valverde (2009) recoge exactamente 1.560 , sin embargo hay algunos más
6. Hablar de originalidad en la época

que no ha tenido en cuenta ya que utilizó la edición decimonónica de Gutiérrez de la Vega (1877), aunque en su trabajo dice que utiliza una edición corregida en 1976 (Valverde, 2009, p. $95)$. No tiene corrección alguna digna de ese nombre, pues lo que utiliza es la reedición prologada por Casariego (Gutiérrez de la Vega, 1877/1976). Terrón Albarrán (2008, p. 258) ha contado 1.613 «unidades forestal-cinegéticas» o montes.

9. Todas las citas al Libro de la montería se hacen con referencia a la edición de Seniff (1983) ya que es la más correcta filológicamente $y$ se ha preparado con criterios científicos. La letra que sigue al número de la página indica la columna: $\mathrm{a}=$ izquierda, b = derecha.

10. El trabajo de Valverde (2009) es póstumo y no quedó dispuesto para su publicación. Su editor, José Antonio de la Fuente Freyre, no se atrevió «a revisar algunos párrafos, ni completar otros [...] ya que habría supuesto alterar, en cierta medida, manuscritos y redacción» (p. 15), aunque «el mismo autor [lo] sugería».

Fradejas Rueda, J. (1992a). Evangelista's Libro de cetrería: a fifteenth-century satire of falconry books. London: Centre for Late Antique and Medieval Studies King's College London.

Fradejas Rueda, J. M. (1992b). El autor del Libro de la montería: historia y comentario de seis siglos de controversia. En: Lucía Megías, J. M., Gracia Alonso, P. y Martín Daza, C. (eds.) Actas // Congreso Internacional de la Asociación Hispánica de Literatura Medieval, Segovia, del 5 al 9 de octubre de 1987. Alcalá de Henares: Universidad de Alcalá, pp. 285-312.

Fradejas Rueda, J. M. (1998). Literatura cetrera de la Edad Media y el Renacimiento español. London: Dept. of Hispanic Studies Queen Mary and Westfield College.

Fradejas Rueda, J. M. (1999). Creençia/ crençia o querencia en el Libro de la Caza. En: Gómez Manzano, P., Carbonero, P. y Casado Velarde, M. (coords.)
Lengua y discurso. Estudios dedicados al profesor Vidal Lamíquiz (vol. 1). Madrid: Arco Libros, pp. 317-322.

Fradejas Rueda, J. M. (2000). Falconers' ornithological classification in medieval Spain. En: Paravicini Bagliani, A. y Van den Abeele, B. (eds.). La chasse au Moyen Age. Société, traités, symboles. Florencia: Sismel - Edizioni del Galluzo, pp. 63-70.

Fradejas Rueda, J. M. (ed.) (2001). Don Juan Manuel y el Libro de la caza. Tordesillas: Instituto de Estudios de Iberoamérica y Portugal / Seminario de Filología Medieval.

Fradejas Rueda, J. M. (2002a). Alina en el Libro de la caza de las aves. ¿Hapax legomenom o error de copia? En: Saralegui Platero, C. y Casado Velarde, M. (coords.) Pulchre, bene, recte: homenaje al prof. Fernando González Ollé (vol. 1). Pamplona: Ediciones Universidad de Navarra. EUNSA, pp. 527-535. 
Fradejas Rueda, J. M. (2002b). Libro de la montería. En: Lucía Megías, J. M. y Alvar Ezquerra, C. (dirs.), Diccionario filológico de literatura medieval española. Textos y transmisión. Madrid: Castalia, pp. 786-791.

Fradejas Rueda, J. M. (2005). La influencia del De arte venandi cum avibus de Federico II en el Libro de la caza de Juan Manuel. En: Los libros de caza. Seminario de Filología Medieval. Tordesillas y Valladolid: Seminario de Filología Medieval - Universidad de Valladolid, pp. 41-54.

García Cañón, P. (2002). La caza en la Montaña noroccidental leonesa durante la baja Edad Media. En: Fradejas Rueda, J. M. (coord.) La caza en la Edad Media. Tordesillas y Valladolid: Instituto de Estudios de Iberoamérica y Portugal Universidad de Valladolid. Seminario de Filología Medieval, pp. 91-98.

Gutiérrez de la Vega, J. (1877). Libro de la montería del rey $d$. Alfonso XI. Madrid: M. Tello.

Gutiérrez de la Vega, J. (ed.) (1877/1976). Libro de la montería del Rey D. Alfonso $X I$. Madrid: Ediciones Velázquez.

Martínez Carrillo, M. de los LI. (1982). EI obispado de Sigüenza en el "Libro de la caza». Un itinerario geográfico. En: Don Juan Manuel. VII Centenario. Murcia: Universidad de Murcia - Academia Alfonso X el Sabio, pp. 187-197.

Quesada López, J. M. (1998). La caza en la prehistoria. Madrid: Arco Libros.
Ruhstaller, S. (1995). Materiales para la lexicología histórica. Estudio y repertorio alfabético de las formas léxicas toponímicas contenidas en el "Libro de la Montería» de Alfonso XI. Tübingen: Niemeyer.

Ruhstaller, S. (1996). Geografía lingüística medieval. El «Libro de la Montería» y su importancia para la delimitación de la difusión areal del léxico hispánico. En: Alonso González, A. (coord.) Actas del III Congreso Internacional de Historia de la Lengua Española, Salamanca, 22-27 de noviembre de 1993 (vol. 2). Madrid: Arco-Libros, pp. 1533-1541.

Ruhstaller, S. (2012). Cómo se elaboró el libro III del "Libro de la montería». Zeitschrift fur Romanische Philologie, 128 (1), pp. 37-56. https://doi. org/10.1515/zrp-2012-0002

Seniff, D. P. (ed.) (1983). Alfonso XI. Libro de la montería. Based on Escorial Ms Y.Il.19. Madison, Wis.: Hispanic Seminary of Medieval Studies.

Terrón Albarrán, M. (ed.) (1984). Pedro de Pedraza Gaitán. Libro de montería. Los Santos de Maimona: Manuel Terrón Albarrán.

Terrón Albarrán, M. (1998). El «Libro de la Montería» y la frontera del reino de Granada. Aportación al estudio de la frontera castellano-nazarí a través de los cazaderos alfonsíes (c. 1342 - c. 1454). En: Memorias de la Real Academia de Extremadura de las Letras y las Artes (vol. 4), pp. 385-620.
Terrón Albarrán, M. (2002). La montería de Alfonso XI (1311-1350). Técnica venatoria y tipología de montes. En: Memorias de la Real Academia de Extremadura de las Letras y las Artes (vol. 5), pp. 349-525.

Terrón Albarrán, M. (2008). Alfonso XI (1311-1350). Las grandes monterías. En: Memorias de la Real Academia de Extremadura de las Letras y las Artes (vol. 6), pp. 255-444.

Thiébaux, M. (1974). The stag of love. The chase in medieval literature. Ithaca: Cornell University Press.

Tilander, G. (ed.) (1971). Gaston Phébus. Livre de chasse. París: Karlshamn.

Trombetti Budriesi, A. L. (ed.) (2000). Federico II. De arte venandi cum avibus = l'arte di cacciare con gli uccelli: edizione e traduzione italiana del ms. lat. 717 della Biblioteca Universitaria di Bologna collazionato con il ms. Pal. lat. 1071 della Biblioteca Apostolica Vaticana. Roma-Bari: Laterza.

Valverde, J. A. (2009). Anotaciones al «Libro de la Montería» del rey Alfonso XI. Salamanca: Ediciones Universidad de Salamanca.

Van den Abeele, B. (1994). La fauconnerie au Moyen Age. Connaissance, affaitage et médecine des oiseaux de chasse d'après les traités latins. Paris: Klincksieck.

Van den Abeele, B. (1996). La littérature cynégétique. Turnhout: Brepols. 